\title{
Bio-pesticides alternative diazinon to control peach fruit fly, Bactrocera zonata (Saunders) (Diptera: Tephritidae)
}

\author{
Ismail R. El-Gendy ${ }^{1 *}$ D, Mona I. El-Banobi ${ }^{2}$ and Juan A. Villanueva-Jimenez ${ }^{3}$
}

\begin{abstract}
Background: The bio-pesticide abamectin has been used to control a large variety of insects, including Diptera species, attributed to its high toxicity with virtually no residual effects on treated crops. Its low residual effect ensures the survival of natural enemies and other non-target organisms. Imidacloprid is also widely used for insect pest control due to its potency and high insect selectivity in comparison to mammals. On the other hand, diazinon has been applied extensively to control immature fruit fly stages, mature larvae, pre-pupae, and pupae in soil drench application, thus, affecting the whole agroecosystem, including the natural enemies.

Results: The toxic effects of abamectin and imidaclopride proposed as a replacement for diazinone in soil treatment, were studied against a laboratory strain of the peach fruit fly (PFF), Bactrocera zonata (Saunders) (Diptera: Tephritidae) under field-caged conditions. Five days old PFF pupae were treated by each pesticide. PFF pupae exhibited different levels of susceptibility to the tested pesticides. Non-significant differences in the pupal mortality rates were obtained between imidacloprid (77.52\%), abamectin (77.22\%), or diazinon (73.89\%). Diazinon and abamectin achieved the highest percentages of total mortality (100\%), followed by imidacloprid (98.89\%). Real mortality rates were mostly concentration-dependent, while the deformed flies rate depended on the chemical sub-group of insecticide and concentration. Additionally, the biochemical studies revealed different acetylcholinesterase enzyme (AChE) inhibition levels caused by the pesticides on the treated flies sampled at 24, 48, and 72 hours post fly emergence.
\end{abstract}

Conclusion: The bio-insecticide abamectin is an option to diazinon for the control of PFF pupae. Also, soil treatment might be an alternative for PFF pupae control.

Keywords: Tephritidae, Fruit flies, Pest control, IPM, Insecticides, Bio-pesticide, Enzymes

\section{Background}

The peach fruit fly (PFF), Bactrocera zonata (Saunders) (Diptera: Tephritidae) is a major destructive tephritid species. Recently, this quarantine pest threats commercial fruits' production in Egypt (EPPO 2002). It is widespread almost in all Governorates of Egypt (Draz et al. 2002).

Pesticides have been usually used for controlling fruit flies with different application methods, such as bait stations and cover spray. The traditional control measure

\footnotetext{
*Correspondence: somaagendy1@gmal.com

${ }^{1}$ Plant Protection Research Institute, Agriculture Research Centre, Giza, Egypt Full list of author information is available at the end of the article
}

using chemical insecticides has several disadvantages, such as insect resistance, residual problems (El-Gendy 2018), and insecticides' inability to penetrate infested fruits to kill larvae. In Egypt, PFF control methods are focused on eradicating adults using the male annihilation technique (FAO/IAEA 2010). Also, abiotic control measures against the pupae include soil moisture management (El-Gendy and AbdAllah 2019). Many areawide IPM programs have applied insecticidal soil drenches under host trees targeting the pre-pupae and pupae (Ekesi et al. 2007). Diazinon has been used effectively in Florida as a soil drench underneath host plants
Springer Open (c) The Author(s). 2021 Open Access This article is licensed under a Creative Commons Attribution 4.0 International License, which permits use, sharing, adaptation, distribution and reproduction in any medium or format, as long as you give appropriate credit to the original author(s) and the source, provide a link to the Creative Commons licence, and indicate if changes were made. The images or other third party material in this article are included in the article's Creative Commons licence, unless indicated otherwise in a credit line to the material. If material is not included in the article's Creative Commons licence and your intended use is not permitted by statutory regulation or exceeds the permitted use, you will need to obtain permission directly from the copyright holder. To view a copy of this licence, visit http://creativecommons.org/licenses/by/4.0/. 
to control fruit fly larvae or gravid adult females. However, chemical control uses increments residues of pesticides in post-harvested fruits. For these reasons, different international organizations, such as the Codex Alimentarius Commission (CAC), the World Health Organization (WHO), and the European Commission (EC), have established and enforced the detection of maximum residue limits (MRLs) in various foods. These are the highest levels of residues expected to be in the food after a pesticide is used according to authorized agricultural regulations. Besides being banned for outdoor residential use, particularly near waterways due to its effects on aquatic organisms in freshwater ecosystems (Stark et al. 2013), diazinon is still used in California and Florida. Several insecticides have been tested in nurseries for fruit fly eradication programs to replace diazinon as a soil treatment (Stark et al. 2014).

Esterases are the most significant enzymes involved in metabolism of many insecticides' groups in insects (Hsu et al. 2004). These hydrolases catalyze the hydrolysis and degradation of a wide range of aliphatic and aromatic esters, choline esters, and organophosphorus compounds (Dauterman 1985). Biochemical tests are useful for monitoring of esterase levels in pest populations or communities. However, AChE plays an essential role in the cholinergic synapses' neurotransmission by catalyzing the acetylcholine neurotransmitter hydrolysis. Organophosphate insecticides (OPs) bind the AChE active site inhibiting the enzyme; this causes an accumulation of acetylcholine in the post-synaptic membrane, preventing the nerve polarization (Oakeshott et al. 2005). After the intensive use of malathion and other OP insecticides in agricultural pest control, resistance mediated by alterations in the AChE has been selected in many insect species (Oakeshott et al. 2005; Mosleh et al. 2011a).

This study aimed to evaluate the toxicity of abamectin and imidacloprid as replacements for diazinon in soil treatments against the pupal stage of $B$. zonata, under field-caged conditions. Furthermore, the in vivo effects of these compounds were studied on acetylcholinesterase activity to elucidate their role in B. zonata control.

\section{Methods}

To find an appropriate replacement for diazinon in soil tratments against the PFF immature stages, a semicontrolled experiment was set in the field.

\section{Study's location}

The present study was carried out in a $200 \mathrm{~m}^{2}$ field plot located at the Directorate of Agriculture, Damanhour city, El-Beheira Governorate, Egypt, in 2017. The field plot hosted 20 Pisidium guajava fruiting trees, about 20 years old, with a plant spacing of $3.5 \times 4 \mathrm{~m}$.

\section{Insect}

The colony of PFF was obtained from the Eradiation of the Peach Fruit Fly Laboratory at Damanhour, ElBeheira Governorate.

\section{Insecticides used}

Three commercial insecticides of different chemical subgroups (IRAC, 2020) were tested against PFF pupae: diazinon (Diazinon 60\% EC, organophosphates), imidacloprid (Admire 70\% WG, neonicotinoids), and avermectin (Abamectin 1.8\%, avermectins).

\section{Procedure}

Concentrations of the tested insecticides were diluted in tap water, four concentrations each: $0.25,1.0,2.0$, and $4.0 \mathrm{ppm}$ for abamectin; 1.5, 3.0, 5.0, and $8.0 \mathrm{ppm}$ for imidacloprid; and $0.07,0.1,0.5$, and $1.0 \mathrm{ppm}$ for diazinon. Five days old PFF pupae (2 days before adults' emergence) were used. The sample size included 600 healthy pupae for each insecticidal treatment and a control, divided in five replicates, 30 pupae for each. Plastic jars $(1000 \mathrm{ml}, 12 \mathrm{~cm}$ wide $\times 11 \mathrm{~cm}$ height $)$ with holes in the bottom (for drainage water) and lined with muslin cloth were filled with sterilized loamy soil, except for the last $50 \mathrm{~mm}$ of height. PFF pupae were transferred to the jars, placed carefully on the soil surface, and covered with $30 \mathrm{~mm}$ height of the same soil type. Each jar was rinsed with an insecticidal concentration until soil saturation point, according to Rhoades (1982); control treatment received water only. Jars were covered by muslin cloths for aeration and maintained in the field covered by guava trees' canopy, and buried in the ground about $7 \mathrm{~cm}$ deep. Daily observations helped to calculate the number of emerged adults. The real pupae mortality rate was calculated, using the following formula:

Pupal mortality no. $=($ no.of unemerged adult flies $/$ no.of treated pupae $) \times 100$

Apparent mortality of adult fly was calculated using the formula:

Adult mortality rate $=($ no.of dead of adult flies $/$ no.of emerged flies $) \times 100$

The total observed mortality rate of pupae was corrected by Abbott's formula (Abbott 1925).

\section{Acetylcholinesterase (AChE) activity assay}

The assay was conducted at the Laboratory of Pesticides Residue Analysis and Toxicity, Damanhour, El-Beheira, Egypt. AChE activity was measured in the emerged flies of PFF pupae treated with $\mathrm{LC}_{50}$ of diazinon, imidacloprid, and abamectin, using the method published by Ellman et al. (1961). AChE activity was determined 24, 48, and $72 \mathrm{~h}$ post the emergence of adults. The emerged flies of treated and un-treated pupae were collected and 
confined in Eppendorf tubes under freezing conditions. Freezing flies were placed on ice and homogenized in a potassium phosphate buffer, $\mathrm{pH} 7.0$ (PPB), using a glass/ Teflon homogenizer at $4{ }^{\circ} \mathrm{C}$. The homogenates were centrifuged at $5000 \mathrm{rpm}$ for $20 \mathrm{~min}$ at $0{ }^{\circ} \mathrm{C}$. A mixture of PPB, the supernatant (crude enzyme), 5,5-dithiol-bis(2-nitrobenzoic acid) (DTNB), and acetylthiocholine iodide (ATChI) was incubated for $30 \mathrm{~min}$ at room temperature $\left(27 \pm 2{ }^{\circ} \mathrm{C}\right)$, followed by optical density (OD) spectrophotometrically measures at $412 \mathrm{~nm}$ using the T80 UV/Vis spectrophotometer. All treatments were replicated five times. Results are presented as inhibition in AChE activity percentages.

\section{Statistical analysis}

Statistical analysis of the AChE inhibition was set as a completely randomized design. A one-way analysis of variance (ANOVA) was conducted for each insecticide and the AChE's inhibition of each treatment. Also, a two-way analysis of AChE inhibition among treatments was performed. A split-plot design was conducted to compare insecticides and their concentrations. The analysis of variance and means separation with TukeyKramer's test $(p<0.05)$ were performed using the CoStat Software (2008, V.6.4).

\section{Results}

\section{Real and apparent mortality of the PFF}

Results in Tables 1, 2, 3, and 4 showed significant differences in the real mortality rates of PFF pupae as well as the deformed adult-fly rates treated in the pupal stage with different diazinon concentrations (pupal death: $F=$ 8.38, $\mathrm{df}=3 ; p=0.007$ : deformed flies; $F=449.53, \mathrm{df}=3$, $p=0.0000)$; however, non-significant differences were found in mortality rates of adult flies among concentrations. Similarly, significant differences based on abamectin concentration were obtained in both real pupal mortality $(F=5.91, \mathrm{df}=3, p=0.02)$ and deformed adult-fly rates $(F=21.69, \mathrm{df}=3, p=0.0003)$, as well as non-significant differences in mortality rates of adult flies. With imidacloprid, the real mortality of pupae, apparent mortality of adult flies, and deformed adult-fly rates were significantly different based on insecticide concentration (pupal mortality: $F=8.38$, $\mathrm{df}=3, p=$ 0.0075; deformed flies: $F=5.67, \mathrm{df}=3, p=0.02$, adultfly mortality: $F=11.76, \mathrm{df}=3, p=0.003$ ).

No differences were obtained among the tested insecticides in the real pupal mortality. However, the highest mortality rates were achieved by imidacloprid $(77.52 \%)$ and abamectin $(77.22 \%)$, both significantly different $(F=$ $16.29, \mathrm{df}=3, p=0.0001)$ than diazinon (73.89\%). The apparent mortality of adult flies were affected significantly by treated insecticides $(F=13.09, \mathrm{df}=2, p=$ $0.017)$ and concentrations $(F=7.25, \mathrm{df}=3, p=0.002)$, with an interaction effect between them on the mortality rate of adult flies $(F=3.02, \mathrm{df}=6, p=0.032)$. Imidacloprid had $35.51 \%$ of deformed adult rates, significantly different $(F=8.94$, df $=2, p=0.033)$ than abamectin (16.41\%) and diazinon (10.12\%).

\section{In vivo inhibition of the PFF AChE by various selected insecticides}

Inhibition rates of $\mathrm{AChE}$ activity (AChE activity on $\mu$ moles of ATChI hydrolyzed per mg of protein in the homogenate per min) in emerged adult flies were different at each insecticidal treatment, and with each tested time (insecticide treatments: $F=1211.21, \mathrm{df}=2, p=$ 0.0000 ; time: $F=132.34, \mathrm{df}=2, p=0.0000$ ). Also, a highly significant interaction was obtained among insecticidal treatments and tested time on $\mathrm{AChE}$ inhibition $(F=143.27, \mathrm{df}=4, p=0.0000)$. Abamectin exhibited a highly significant inhibition of AChE activity, followed

Table 1 The real and apparent mortalities, and deformed flies percentages of the peach fruit fly, Bactrocera zonata, treated with diazinon pesticide at pupal stage

\begin{tabular}{|c|c|c|c|c|}
\hline Concentrations (ppm) & RM of pupae \% & AM of adults $\%$ & Total mortality \% & Deformed flies \% \\
\hline 0.07 & $43.33 \mathrm{~b}$ & $100.0 \mathrm{a}$ & $100.0 a$ & $23.84 \mathrm{a}$ \\
\hline 0.10 & $68.88 a b$ & $97.42 \mathrm{a}$ & $100.0 \mathrm{a}$ & $16.16 b$ \\
\hline 0.50 & 88.88 a & $100.0 a$ & $100.0 \mathrm{a}$ & $0.0 \mathrm{c}$ \\
\hline 1.00 & $94.44 \mathrm{a}$ & $100.0 \mathrm{a}$ & $100.0 \mathrm{a}$ & $0.0 \mathrm{c}$ \\
\hline Df & 3.0 & 3.0 & 3.0 & 3.0 \\
\hline SS & 4817.53 & 15.05 & 0.0 & 1305.31 \\
\hline MS & 1605.84 & 5.005 & 0.0 & 435.103 \\
\hline F & 8.38 & 1.44 & - & 449.530 \\
\hline$P$ value & 0.007 & 0.12 & - & 0.0 \\
\hline L.S.D. & 26.06 & 4.21 & 4.21 & 1.85 \\
\hline
\end{tabular}

Values with the same letters are not significantly different, L.S.D. least significant difference; RM real mortality; $A M$ apparent mortality, ppm parts per million 
Table 2 The real and apparent mortalities, and deformed flies percentages of the peach fruit fly, Bactrocera zonata, treated with abamectin pesticide at pupal stage

\begin{tabular}{lllll}
\hline Concentrations $(\mathbf{p p m})$ & RM of pupae\% & AM of adults \% & Total mortality \% & Deformed flies \% \\
\hline 0.25 & $52.22 \mathrm{~b}$ & $100.0 \mathrm{a}$ & $100.0 \mathrm{a}$ & $2.22 \mathrm{c}$ \\
1.00 & $78.88 \mathrm{ab}$ & $100.0 \mathrm{a}$ & $100.0 \mathrm{a}$ & $36.55 \mathrm{a}$ \\
2.00 & $87.77 \mathrm{a}$ & $100.0 \mathrm{a}$ & $100.0 \mathrm{a}$ & $8.33 \mathrm{bc}$ \\
4.00 & $90.00 \mathrm{a}$ & $100.0 \mathrm{a}$ & $100.0 \mathrm{a}$ & $18.51 \mathrm{~b}$ \\
Df & 3.0 & 3.0 & 3.0 & 3.0 \\
SS & 2707.4 & 0.0 & 0.0 & 2030.3 \\
MS & 902.47 & 0.0 & 0.0 & 676.78 \\
F & 5.91 & & & 21.69 \\
P value & 0.02 & & & 0.0003 \\
L.S.D. & 23.27 & 0.0 & 0.0 & 10.52 \\
\hline
\end{tabular}

Values with the same letters are not significantly different, L.S.D. least significant difference; $R M$ real mortality; $A M$ apparent mortality, $p p m$ parts per million

by diazinon and imidacloprid, according to the general mean inhibition obtained along the tested time. Results illustrated in Fig. 1 showed that abamectin had a high and significant inhibition of $\mathrm{AChE}$ activity, in relation to the tested time ( 24 h, 20.46\%; 48 h, 21.79\%; 72 h, 21.87\% inhibition) $(F=53.80, \mathrm{df}=2, p=0.0004)$. Also, AChE activity was increasingly and significantly inhibited by diazinon $(F=233.03, \mathrm{df}=2, p=0.0001$ at $24(10.65 \%), 48$ (11.89\%), and $72 \mathrm{~h}$ (22.83\% inhibition) (Fig. 2). However, on the adult flies treated with imidacloprid, AChE was significantly inhibited $(F=31.75, \mathrm{df}=2, p=0.0014)$, but inhibition recorded was as follows: at $24 \mathrm{~h}, 10.02 \% ; 48 \mathrm{~h}$, 3.04\%, and 72 h, 6.46\% (Fig. 3).

\section{Discussion}

Eliminating the adult tephritid emergence from the soil can work side by side with other control measures such as chemical insecticides, bait sprays, soil moisture management, soil compaction, sterile insect release, and male annihilation in eradication programs (Ndlela et al. 2016; El-Gendy and AbdAllah 2019, 2020). In the present study, the tested insecticides were effective in PFF eradication, with different toxicity against PFF pupae and adult flies. Pupal mortality rates depended on the chemical sub-group of the insecticide, reflecting 90$99 \%$ of the variability, according to the determination coefficient. It also depended on the insecticidal concentration. For instance, the highest real mortality was obtained with the highest concentration of imidacloprid (99.0\%), followed by diazinon (94.44\%), and then abamectin (90.0\%). Furthermore, diazinon and abamectin can eliminate adult flies at any of the tested concentrations. However, the highest concentrations of imidacloprid are needed to perform similarly.

Diazinon was the most toxic insecticide for the pupal stage, followed by the two biopesticides abamectin and

Table 3 The real and apparent mortalities, and deformed flies percentages of the peach fruit fly, Bactrocera zonata, treated with imidacloprid pesticide in pupal stage

\begin{tabular}{|c|c|c|c|c|}
\hline Concentrations (ppm) & RM of pupae \% & AM of adults $\%$ & Total mortality \% & Deformed flies \% \\
\hline 1.5 & $66.64 \mathrm{~b}$ & $097.22 \mathrm{ab}$ & $96.66 \mathrm{~b}$ & $30.55 \mathrm{a}$ \\
\hline 3.0 & $71.01 \mathrm{~b}$ & $093.33 \mathrm{~b}$ & $98.88 a b$ & $40.25 \mathrm{a}$ \\
\hline 5.0 & $73.33 \mathrm{~b}$ & 100.0a & $100.0 \mathrm{a}$ & $32.33 a b$ \\
\hline 8.0 & $99.0 \mathrm{a}$ & $100.0 a$ & $100.0 \mathrm{a}$ & $38.88 a b$ \\
\hline Df & 3.0 & 3.0 & 3.0 & 3.0 \\
\hline SS & 1915.1 & 89.58 & 22.31 & 205.77 \\
\hline MS & 638.37 & 29.86 & 7.43 & 68.59 \\
\hline F & 8.38 & 11.76 & 8.00 & 5.67 \\
\hline$P$ value & 0.0075 & 0.003 & 0.009 & 0.02 \\
\hline L.S.D. & 16.43 & 3.0 & 1.82 & 6.55 \\
\hline
\end{tabular}

Values with the same letters are not significantly different, L.S.D. least significant difference; $R M$ real mortality; $A M$ apparent mortality, ppm parts per million 
Table 4 The real and apparent mortalities, and deformed flies percentages of the peach fruit fly, Bactrocera zonata, treated with pesticides in pupal stage

\begin{tabular}{lllll}
\hline Insecticide & Real mortality of pupae \% & Apparent mortality of adults \% & Total mortality \% & Deformed flies \% \\
\hline Diazinon & $73.89 \mathrm{a}$ & $99.35 \mathrm{ab}$ & $100.0 \mathrm{a}$ & $10.12 \mathrm{~b}$ \\
Abamectin & $77.22 \mathrm{a}$ & $100.0 \mathrm{a}$ & $100.0 \mathrm{a}$ & $16.41 \mathrm{ab}$ \\
Imidacloprid & $77.52 \mathrm{a}$ & $97.64 \mathrm{~b}$ & $98.89 \mathrm{~b}$ & $35.51 \mathrm{a}$ \\
Df & 2.0 & 2.0 & 2.0 & 2.0 \\
F & 0.125 & 3.58 & 5.5 & 4.40 \\
P value & 0.88 & 0.039 & 0.009 & 0.02 \\
L.S.D. & 10.17 & 1.85 & 0.79 & 18.13 \\
\hline
\end{tabular}

Values with the same letters are not significantly different, L.S.D. least significant difference; $R M$ real mortality; $A M$ apparent mortality

then imidacloprid. These results are in agreement with the results of Stark et al. (2014) who mentioned that diazinon, as a soil treatment, was of the most toxic insecticides against Ceratitis capitata pupae, but neither $B$. dorsalis nor B. cucurbitae. In parallel, diazinon was the most toxic insecticide for PFF male and female flies with 0.20 and $0.26 \mathrm{ppm}$ at $24 \mathrm{~h}$ post-treatment, followed by malathion, lufenuron, and methoxyfenozide insecticides (Mosleh et al. 2011). Also, Abdullahi et al. (2020) revealed that the diazinon was the most toxicity of the insecticides against $B$. invadens, followed by chlorpyrifos, cypermethrin + dimethoate, and deltamethrin, respectively. In the same line, Stark et al. (1992) found that puparium formation was pesticide concentrationdependent, affected by diazinon, not by cyromazine.

In many fruit fly studies, abamectin $1.8 \%$ EC exhibited a high efficiency against various fruit flies stages. According to Halawa et al. (2013), in sandy-soil treatments against 3 days old pupae of PFF and C. capitata, abamectin was the most effective treatment, compared to lufenuron or lufenuron + emamectin benzoate. Also, abamectin was of the most effective insecticides against
B. dorsalis adults (Wang et al. 2013). However, imidacloprid obtained the lowest efficiency of the tested insecticides, emamectin benzoate, trichlorfon, and $\lambda$ cyhalothrin, against PFF (Khan and Naveed 2016).

PFF response to the tested insecticides varied significantly, which may be due to the insecticide type, mode of action, or residual activity. The present findings are consistent with El-Aw et al. (2008), who reported different toxicity rates of pesticides against PFF adults, where methomyl was the most effective insecticide, followed by thiamethoxam, spinosyn, and malathion. Stark et al. (2014) mentioned that the most effective insecticides as soil treatments for C. capitata, B. cucurbitae, and B. dorsalis pupae were spinosad, lambda-cyhalothrin, permethrin, tefluthrin, and diazinon with no significant difference. However, Raga et al. (2018) mentioned that Anastrepha fraterculus (Wied.) and A. grandis (Macquart) exhibited similar susceptibility to acetamiprid, deltamethrin, flypyradifurone, imidacloprid, phosmet, thiamethoxam, and zeta-cypermethrin.

Recently, the Agriculture Pesticides Committee in Egypt banned diazinon for agricultural uses. However,

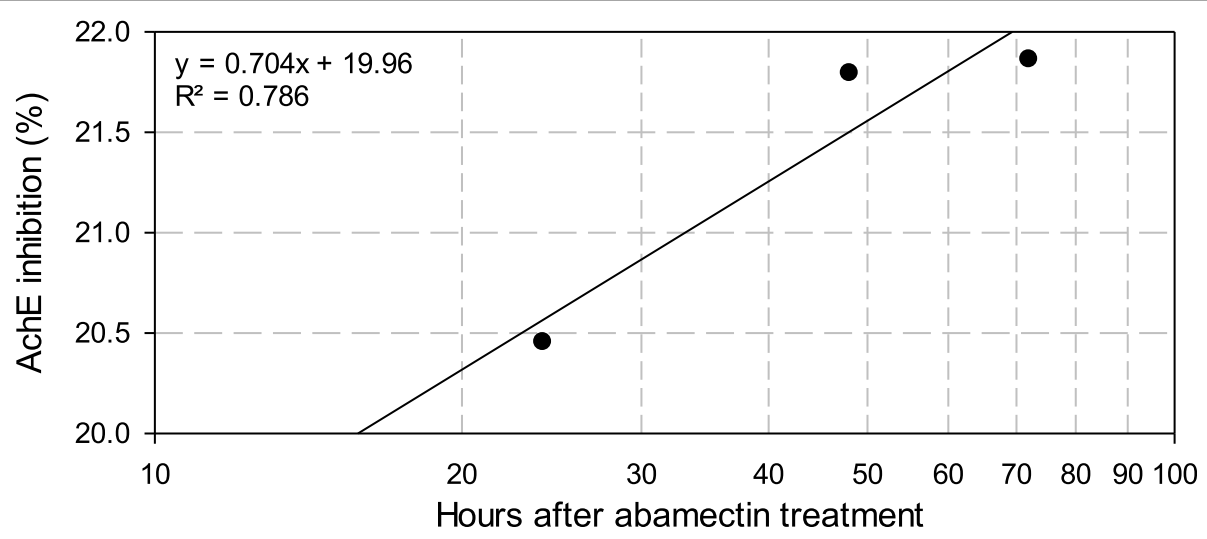

Fig. 1 Inhibition of AChE activity in Bactrocera zonata pupae treated with abamectin 


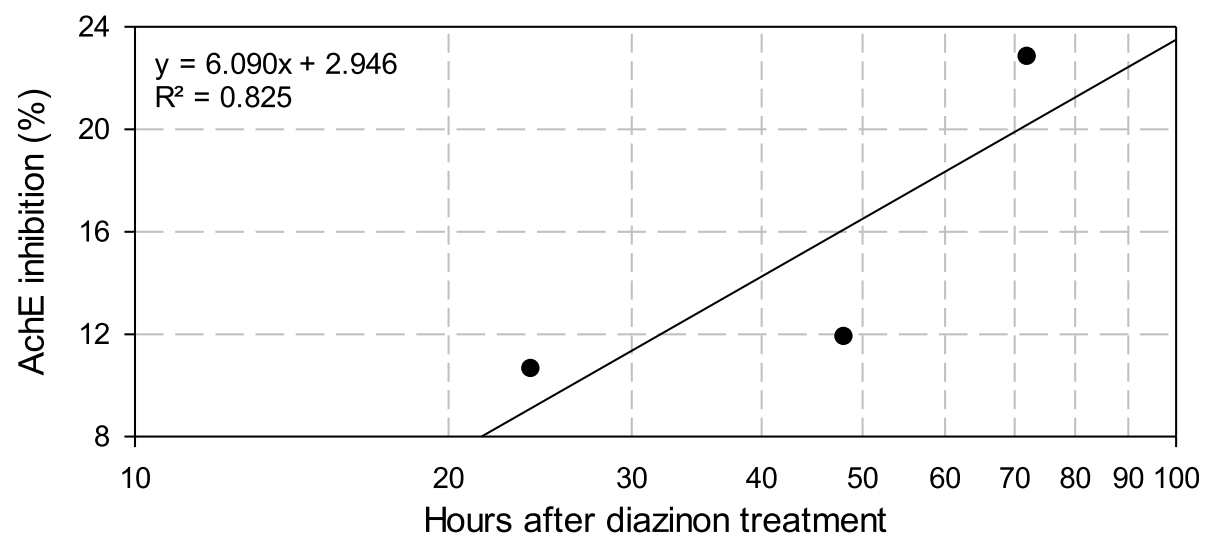

Fig. 2 Inhibition of AChE activity in Bactrocera zonata pupae treated with diazinon

residues of diazinon have been found in some Egyptian areas. Diazinon was detected in water samples collected from Lake Qarun and drainage canal in Damietta, Egypt (Abdel-Halim et al. 2006). Its residual effect extended to crop fruits, where fruit samples in oranges and grapes contained $0.01 \mathrm{mg} / \mathrm{kg}$ of diazinon (Gad Alla et al. 2015). Hence, it is clear that the importance of finding effective bio-insecticides against immature stages of fruit flies other than diazinon as soil treatments, such as abamectin.

The present study also revealed a decrease in fly AChE activity of previously insecticide-treated pupae. The percentages of AChE activity inhibition were in ascending order for abamectin, diazinon, and imidacloprid. The activity of AChE in treated PFF with malathion, diazinon, methoxyfenozoide, and lufenuron decreased compared to the control (Mosleh et al. 2011), as well as variations among tested insecticides in AChE activities in PFF adult flies treated as pupae were reported (Halawa et al. 2013). The present findings of AChE inhibition by the tested insecticides is found to be dependent on time after treatment, which was positively correlated to the tested time posttreatment in both abamectin and diazinon insecticides, 24, 48, and $72 \mathrm{~h}$, with a maximum inhibition at $72 \mathrm{~h}$, followed by 48 and $24 \mathrm{~h}$, respectively. As for imidacloprid, AChE inhibition was high after $24 \mathrm{~h}$, followed by 72 and then $48 \mathrm{~h}$.

As a bio-pesticide, abamectin had a high efficacy eliminating immature stages of PFF in the soil, as well as the emerged flies from the treated pupae. Thus, abamectin soil treatment abamectin might be used as an alternative to diazinon for the control program of PFF.

\section{Conclusion}

The biopesticide abamectin might be in soil treatments in PFF control, as an alternative to diazinon. The highest percentage of pupal elimination was obtained by imidacloprid, followed by abamectin and diazinon. Diazinon, abamectin, and imidacloprid achieved high percentages of total mortality of PFF.

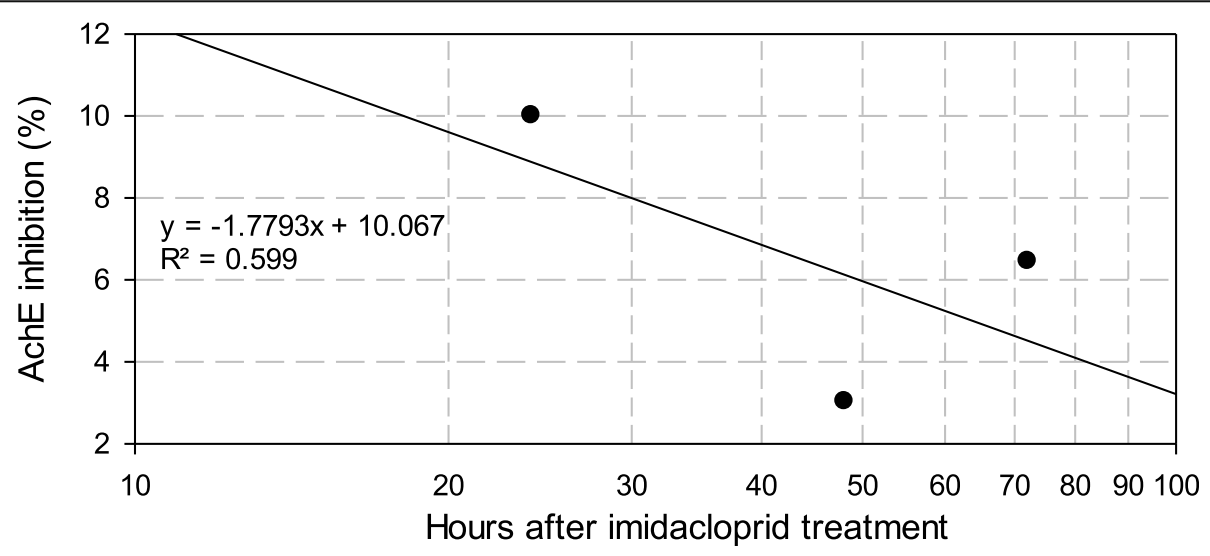

Fig. 3 Inhibition of AChE activity in Bactrocer zonata pupae treated with imidacloprid 


\section{Abbreviations}

PFF: Peach fruit fly; LC 50 : Lethal insecticide concentrations causing 50\% mortality; AChE: Acetylcholinesterase enzyme; ppm: Part per million; IPM: Integrated pest management; IRAC: Insecticide Resistance Action Committee

\section{Acknowledgements}

The authors acknowledge Mrs. Walely N., Eradiation of the Peach Fruit Fly Laboratory at Damanhour, El-Beheira, for their helping during these experiments.

\section{Significant statement}

This research specifically showed that the bio-pesticide abamectin could be used to control PFF pupae, as an alternative to diazinon in soil treatments, which will make a significant contribution to the protection of Egyptian agro-ecosystems.

\section{Authors' contributions}

$\mathrm{IR}, \mathrm{MI}$, and JA planned the experiments. IR and $\mathrm{MI}$ carried out the experiments. IR analyzed the dada. IR wrote the manuscript with support of $\mathrm{MI}$ and JA. IR, MI, and JA discussed the results and contributed the final manuscript. All authors have read and approved the manuscript to publish.

\section{Funding}

Not applicable.

\section{Availability of data and materials}

The datasets used and/or analyzed during the current study are available from the authors on fair request.

\section{Declarations}

\section{Ethics approval and consent to participate}

Not applicable

\section{Consent for publication}

Not applicable

\section{Competing interests}

The authors have declared that no competing interests exists.

\section{Author details}

${ }^{1}$ Plant Protection Research Institute, Agriculture Research Centre, Giza, Egypt. ${ }^{2}$ Plant Protection Department, Faculty of Agriculture, Damanhour University, Damanhour, Egypt. ${ }^{3}$ Colegio de Postgraduados, Campus Veracruz, Veracruz, Mexico.

Received: 18 November 2020 Accepted: 3 March 2021

\section{Published online: 11 March 2021}

\section{References}

Abbott WS (1925) A method of computing the effectiveness of an insecticide. J. Econ. Entomol. 18(2):265-267. https://doi.org/10.1093/jee/18.2.265a

Abdel-Halim K, Salama A, El-Kahateeb E, Bakry NM (2006) Organophosphorus pollutants (OPP) in aquatic environment at Damietta governorate, Egypt: implications for monitoring and biomarker responses. Chemo. 63:1491-1498

Abdullahi G, Obeng-Ofori D, Afreh-Nuamah K, Billah MK (2020) Acute and residual concentration-dependent toxicities of some selected insecticides to adult Bactrocera invadens Drew, Tsuruta and White (Diptera: Tephritidae). J Basic Appl Zool 81:18. https://doi.org/10.1186/s41936-020-00144-4

CoStat Software (2008) Version 6.4, CoHort software, Monetery, CA, USA

Dauterman WC (1985) Insect metabolism: extramicrosomal. In: Kerkut GA, Gilbert LI (eds) Comprehensive insect physiology, biochemistry and pharmacology, vol 12. Pergamon, Oxford, pp 713-730 Available at https://d-nb.info/851 000223/04

Draz KAA, Hashem AG, El-Aw MA, El-Gendy IR (2002) Monitoring the changes in the population activity of peach fruit fly, Bactrocera zonata (Saunders) at certain agro-ecosystem in Egypt. In: Proceedings of the 2nd International Conference for Plant Protection Research Institute, Cairo, 21-24 December 2002, pp 570-575 Available at https://www.researchgate.net/publication/274 699918
Ekesi S, Dimbi S, Maniania NK (2007) The role of entomopathogenic fungi in the integrated management of fruit flies (Diptera: Tephritidae) with emphasis on species occurring in Africa. In: Ekesi S, Maniania NK (eds) Use of Entomopathogenic Fungi in Biological Pest Management. Research SignPost, Kerala, India, pp 239-274 Available at: https://www.researchgate.net/publication/297758806

El-Aw MAM, Draz KAA, Hashem AG, El-Gendy IR (2008) Mortality comparison among spinosad-, actara-, malathion-, and methomyl-containing baits against peach fruit fly, Bactrocera zonata Saunders (Diptera: Tephritidae) under laboratory conditions. J Appl Sci Res 4:216-223 Available at https://www.semanticscholar. org/paper/Mortality-Comparison-Among-Spinosad-\%2C-Actara-\%2C-and-El-AwEl-gendy/496dd43402ad2338741 b6be6b1a9967a4366420b

El-Gendy IR (2018) Insecticide resistance of a field strain of Mediterranean fruit fly Ceratitis capitata (Wiedemann) in Egypt. J Appl Sci. 18:25-32. https://doi. org/10.3923/jas.2018.25.32

El-Gendy IR, AbdAllah AM (2019) Effect of soil type and soil water content levels on pupal mortality of the peach fruit fly [Bactrocera zonata (Saunders)] (Diptera: Tephritidae). Int J Pest Manage 65(2):154-160. https://doi.org/10.1 080/09670874.2018.1485988

El-Gendy IR, AbdAllah AM (2020) Soil compaction, moisture content and pupal burial depth as a new control strategy of peach fruit fly Bactrocera zonata (Diptera: Tephritidae). Egypt. J. Plant Prot. Res. Inst 3:621-635

Ellman GL, Courtney D, Andres V, Featherstone RM (1961) A new and rapid colorimetric determination of acetylcholinesterase activity. Biochem Pharmacol. 7:88-95. https://doi.org/10.1016/0006-2952(61)90145-9

EPPO (2002) Report of EPPO workshop on Bactrocera zonata. European and Mediterranean Plant Protection Organization, Paris Available at http://www. eppo.int/QUARANTINE/special_topics/bactrocera_zonata/bactrocera.htm

FAO/IAEA [Agriculture Organization/International Atomic Energy Agency] (2010) Studying the peach fruit fly: Bactrocera zonata. https://www.ukessays.com/ essays/biology/studying-the-peach-fruit-fly-bactrocerazonata-biology-essay. php?vref=1>. (Accessed April 2017).

Gad Alla SA, Almaz MM, Thabet WM, Mohammed MN (2015) Evaluation of pesticide residues in some Egyptian fruits. Int J Environ. 04:87-97

Halawa SM, El-Hosary RAA, Mosallam AMZ, El-Khayat EF, Ismail MMS (2013) Toxicological, biological and biochemical effects of certain insecticides on Bactrocera zonata (Saunders) (Diptera, Tephritidae). Am Eurasian J Toxicol Sci 5:55-65. https://doi.org/10.17221/51/2009-PPS

Hsu JC, Feng H-T, Wu W-J (2004) Resistance and synergistic effects of insecticides in Bactrocera dorsalis (Diptera: Tephritidae) in Taiwan. J. Econ. Entomol. 97: 1682-1688. https://doi.org/10.1603/0022-0493-97.5.1682

IRAC Insecticide Resistance Action Committee (2020) Mode of Action Classification Scheme. Accessed March 2020, version 9.4. http://www.irac-online.org

Khan RA, Naveed M (2016) Evaluation of comparative toxicity of differen insecticides against fruit fly, Bactrocera zonata Saunders (Diptera: Tephritidae). Pakistan J. Zool. 49:399-401

Mosleh YY, Moussa SFM, Mohamed LHY (2011) Comparative toxicity of certain pesticides to peach fruit fly, Bactrocera zonata Saunders (Diptera: Tephritidae) under laboratory conditions. Plant Protect. Sci 47:115-120. https://doi.org/1 $0.17221 / 52 / 2009-P P S$

Mosleh YY, Yousry LH, Abo-El-Elaa A (2011a) Toxicological and biochemical effects of some insecticides on peach fly, Bactrocera zonata (Diptera: Tephritidae). Plant Protec. Sci 47:121-130. https://doi.org/10.17221/51/2009-PPS

Ndlela S, Mohamed SA, Ndegwa P, Ekesi S (2016) Male annihilation technique using methyl eugenol for field suppression of Bactrocera dorsalis (Hendel) (Diptera: Tephritidae) on mango in Kenya. African Entomol 24:437-447

Oakeshott JG, Claudianos C, Campbell PM, Newcomb R, Russell RJ (2005) Biochemical genetics and genomics of insect esterases. In: latrou K, Gill SS (eds) Gilbert LI. Comprehensive Molecular Insect Science, Elsevier, Oxford, UK pp 309-381. https://doi.org/10.1016/B0-44-451924-6/00073-9

Raga A, Galdino LT, Silva SB, Baldo FB, Sato ME (2018) Comparison of insecticide toxicity in adults of the fruit flies Anastrepha fraterculus (Wied.) and Anastrepha grandis (Macquart) (Tephritidae). J Exp Agric Int. 25:1-8

Rhoades JD (1982) Soluble salts. PP: 167-179. In: Page AL (ed) Methods of soil analysis. part 2 chemical and microbiological properties. Agronomy.Vol 9 (2nded). American society of agronomy, Madison, WJ Available at http:// ucce.ucdavis.edu/universal/printedprogpageshow.cfm?pagenum= 0\&progkey $=1360 \&$ county $=5120$

Stark JD, Vargas Rl, Messing RH, Purcell M (1992) Effects of cyromazine and diazinon on three economically important Hawaiian tephritid fruit flies (Diptera: Tephritidae) and their endoparasitoids (Hymenoptera: Braconidae). J. Econ. Entomol. 85(5):1687-1694 
Stark JD, Vargas Rl, Souder S, Fox AJ, Smith TR, Mackey B (2013) A comparison of the bioinsecticide, spinosad, the semi-synthetic insecticide, spinetoram and synthetic insecticides as soil drenches for control of tephritid fruit flies. Biopestic. Int. 9:120-126 Available at https://www.researchgate.net/publica tion/262298429

Stark JD, Vargas RI, Souder SK, Fox AJ, Smith TR, Leblanc L, Mackey B (2014) Stimulated field applications of insecticide soil drenches for control of tephritid fruit flies. Biopestic. Int. 10:136-142 Available at https://www.resea rchgate.net/profile/Luc_Leblanc2/publication/274779864

Wang JJ, Wei D, Dou W, Hu F, Liu WF, Wang JJ (2013) Toxicities and synergistic effects of several insecticides against the oriental fruit fly (Diptera:

Tephritidae). J. Econ. Entomol. 106:970-978. https://doi.org/10.1603/ec12434

\section{Publisher's Note}

Springer Nature remains neutral with regard to jurisdictional claims in published maps and institutional affiliations.

\section{Submit your manuscript to a SpringerOpen ${ }^{\circ}$ journal and benefit from:}

- Convenient online submission

- Rigorous peer review

- Open access: articles freely available online

High visibility within the field

- Retaining the copyright to your article

Submit your next manuscript at $\boldsymbol{\nabla}$ springeropen.com 